\title{
Experiências de Engorda de Frangos (*)
}

\section{II}

Prof. A. P. TORRES e engenheirando J. M. SANTOS

Escola Superior de Agricultura "Luiz de Queiroz"

INDICE

1 —Introdução $\ldots \ldots \ldots \ldots$

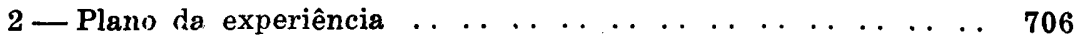

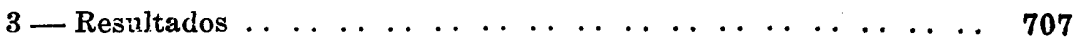

4 - Discussão $\ldots \ldots \ldots \ldots$

5 - Resumo e conclusões $\ldots \ldots \ldots \ldots$

6 - Abstract . . . . . . . . . . . . . . . . . . . . . . . . . . . . 710

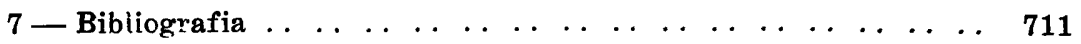

(*) Trabalho da Seção de Avicultura e Cunicultura 


\section{INTRODUÇÃO}

Uma primeira experiência realizada na Seção de Avicultura e Cunicultura, da E. S. A. "Luiz de Queiroz", U. S. P., por TORRES \& TRIVELIN (1), revelou que o maior aumento de pêso no preparo final de frangos para o mercado - processo entre nós chamado "engorda" - se verificava nos primeiros sete dias e lhes pareceu que 14 dias seria um periodo grande e anti-econômico, pois nesse período a intensidade de aumento de pêso já está bem diminuida.

JULL \& MAN (2) acham que 10 dias é um período conveniente para raças mais pesadas e 14 para as raças leves, o que é admitido por outros autores.

Finalmente EWING (3) chama atenção para o fato de certos alimentos produzirem uma engorda mais rápida, em 7 dias, não produzindo aumentos posteriormente, fato observado por TORRES \& TRIVELIN (1), enquanto outros alimentos continuam a produzir aumentos até 14 dias.

\section{PLANO DA EXPERIENCIA}

$\mathrm{Na}$ presente experiência foram usados trinta frangos da raça Rhode I. Red, com um pêso médio de 1.745 gs., tendo um sido eliminado na quarta pesagem por motivo de moléstia (leucose), ficando 29 .

Essas aves foram colocadas 2 a 2, em 15 gaiolas de nosso biotério, recebendo a seguinte ração de alimentos comuns na alimentação de aves, nesta região:

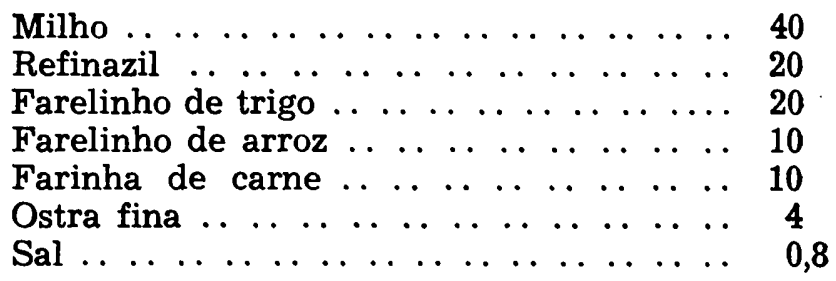

Esta ração, que contêm aproximadamente $17,0 \%$ de proteina bruta não apresenta particularidade especial para ser recomendada. Foi moida finamente, e umidecida no momento de ser empregada afim de homogenizá-la.

O consumo de ração foi de $56 \mathrm{ks}$. em 22 dias, dando portanto uma média diária de 88 gs. por cabeça. 
Cada frango recebeu um número e foi pesado individualmente. A experiência teve início no dia 31-3-50, quando foi feita a 1a. pesagem; a 2a. pesagem verificou-se quatro dias após, e as demais cada dois dias, perfazendo um total de 11 pesagens e 10 períodos.

Determinou-se posteriormente a percentagem de aumento verificado, em cada período, sôbre o pêso inicial nesse intervalo.

Foram determinados os aumentos médios nos diferentes períodos para se verificar a economia do ganho médio.

Estudou-se a variação individual de aumento $\%$, sôbre o pêso inicial afim de mostrar a variação decorrente da individualidade.

Finalmente, com os dados obtidos, os AA. construiram um gráfico (́pág. 709) que permite ao leitor observar o proporção de frangos que deixa de crescer e chega mesmo a perder pêso, à medida que progride a engorda.

\section{RESULTADOS}

No quadro abaixo apresentam resumidamente os resultados obtidos com as pesagens. $O$ pêso inicial foi de $50.600 \mathrm{gs}$. para 29 pintos, com média de 1.745 e o final 65.700 gs. com 2.266 de média, dando um aumento médio de 521 gs., que corresponde a $30 \%$ do pêso inicial: Este resultado é satisfatório, embora pudesse ser superado. Observe-se contudo que o mesmo pêso é obtido em 16 dias (67.750), o que confirma ser inutil prolongar a engorda além dêsse período.

QUADRO I

\begin{tabular}{l|r|r|r|r}
\hline & \multicolumn{2}{|c|}{ Pêso } & \multicolumn{2}{c}{ Aumentos } \\
\cline { 2 - 5 } Período & Total & Médio & Total & $\%$ \\
\hline & & & & \\
\cline { 5 - 5 } Aos 4 dias & 55.050 & 1.898 & 4.450 & 8.79 \\
Aos 6 dias & 57.550 & 1.984 & 2.500 & 4.54 \\
Aos 8 dias & 59.000 & 2.094 & 1.450 & 2.52 \\
Aos 10 dias & 61.700 & 2.128 & 2.700 & 4.58 \\
Aos 12 dias & 63.450 & 2.188 & 1.750 & 2.84 \\
Aos 14 dias & 64.600 & 2.228 & 1.150 & 1.81 \\
Aos 16 dias & 65.750 & 2.267 & 1.150 & 1.78 \\
Aos 18 dias & 66.700 & 2.300 & 950 & 1.44 \\
Aos 20 dias & 66.250 & 2.284 & -450 & -0.67 \\
Aos 22 dias & 65.700 & 2.266 & -550 & -0.82 \\
\hline
\end{tabular}


Em 12 dias obteve-se um aumento médio de 443 gs. que corresponde a $25,4 \%$ do pêso inicial e aos 14 dias 483 gs. ou 27,7 do pêso inicial.

A uniformidade dos aumentos finais observado é razoável como se pode observar do quadro abaixo :

QUADRO II

Classificação final dos aumentos individuais expressos em porcentagens

\begin{tabular}{|c|c|c|c|c|c|}
\hline \multirow{2}{*}{ 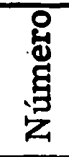 } & \multicolumn{2}{|c|}{$\%$ de aumento } & \multirow{2}{*}{ Número } & \multicolumn{2}{|c|}{$\%$ de aumento } \\
\hline & Em 12 dias & Em 22 dias & & Em 12 dias & Em 22 dias \\
\hline $\begin{array}{r}462 \\
202 \\
255 \\
154 \\
358 \\
468 \\
419 \\
441 \\
257 \\
99 \\
254 \\
334 \\
245 \\
315 \\
472\end{array}$ & $\begin{array}{l}36,6 \\
46,2 \\
37,5 \\
31,2 \\
25,9 \\
30,0 \\
36,4 \\
30,3 \\
28,9 \\
25,7 \\
25,0 \\
24,3 \\
27,1 \\
24,3 \\
25,0\end{array}$ & $\begin{array}{l}49,97 \\
46,15 \\
43,74 \\
43,73 \\
40,74 \\
39,96 \\
39,39 \\
36,36 \\
31,57 \\
31,42 \\
30,55 \\
29,72 \\
29,72 \\
29,71 \\
27,76\end{array}$ & $\begin{array}{r}317 \\
414 \\
89 \\
450 \\
440 \\
492 \\
413 \\
238 \\
201 \\
424 \\
485 \\
335 \\
474 \\
259\end{array}$ & $\begin{array}{l}21,6 \\
26,7 \\
23,7 \\
20,9 \\
17,5 \\
21,9 \\
21,6 \\
21,4 \\
21,1 \\
21,1 \\
23,5 \\
23,1 \\
22,2 \\
18,2\end{array}$ & $\begin{array}{l}27,27 \\
26,64 \\
26,30 \\
25,57 \\
25,00 \\
24,99 \\
24,31 \\
23,80 \\
23,67 \\
23,67 \\
23,52 \\
23,07 \\
22,22 \\
18,18\end{array}$ \\
\hline
\end{tabular}

\section{DISCUSSAOO}

Pode-se observar pelo exame do Quadro I que o aumento total verificado entre o $12^{\circ}$. e o $16^{\circ}$. dia, corresponde a 2,300 de frango, que, ao preço médio de $\operatorname{Cr} \$ 16,00 \circ \mathrm{k}$., representará $\mathrm{Cr} \$ 36,80$. Si os 29 frangos comerem na base de $88 \mathrm{gs}$. por dia e por cabeça, consumirão neste periodo $10,100 \mathrm{ks}$. de de ração que ao preço de $\mathrm{Cr} \$ 1,50$ o $\mathrm{k}$, representará $\mathrm{Cr} \$ 15,15$ no total, o que ainda é econômico.

Concluimos que para frangos R. I. R. e com uma ração de base semelhante o período ideal de engorda será de 12 dias podendo prolongar-se, no máximo por mais 4 dias sem grande inconveniente econômico. Como o criador não pode sempre dispor dos frangos em dia certo, êle deverá fixars êsses limites, mínimo de 12 e máximo de 16 dias para a venda de seus frangos a pêso. 
A percentagenm de aumento cai bruscamente a partir dos 12 dias e permanece mais ou menos constante por três períodos.

GRAFICO I dias $\begin{array}{llllllllll}4 & 6 & 8 & 10 & 12 & 14 & 16 & 18 & 20 & 22\end{array}$

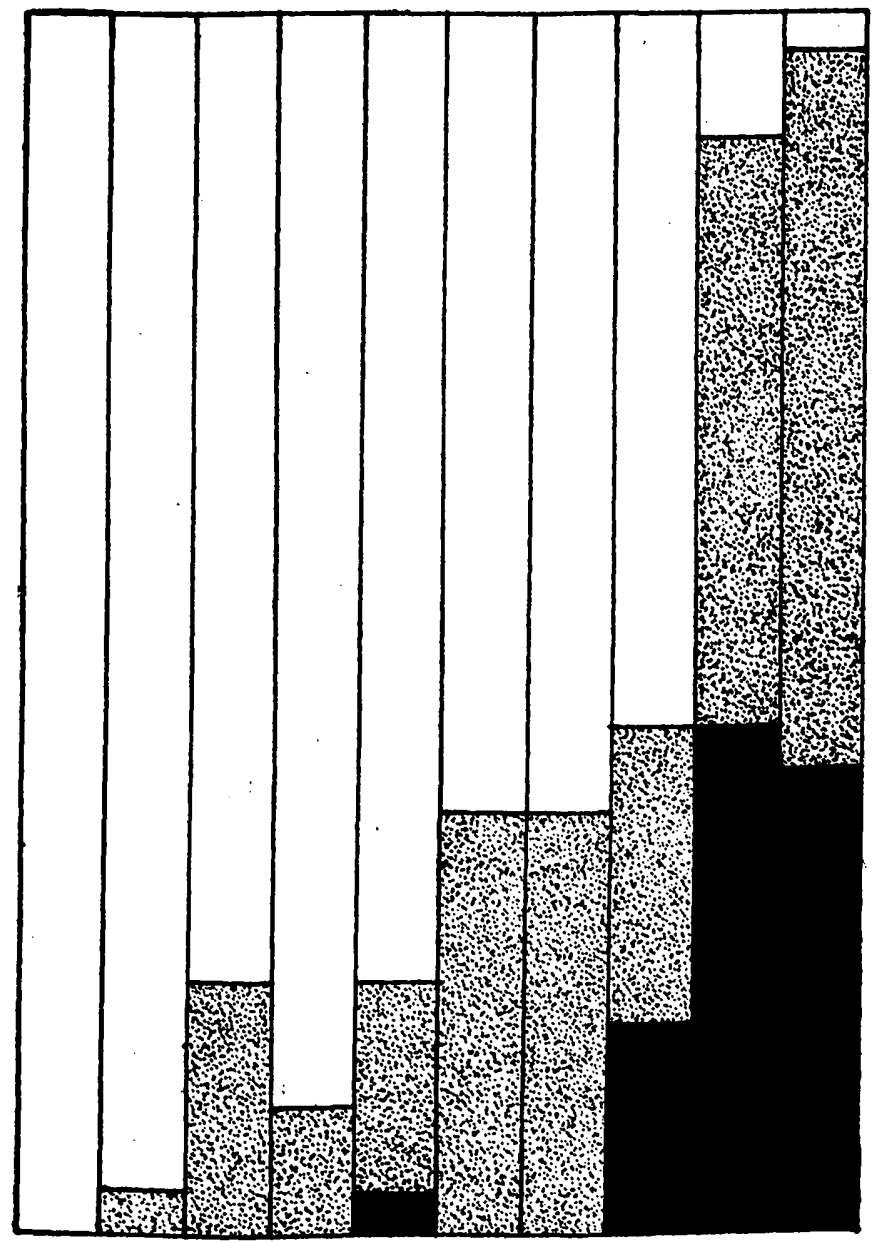

DIMINUIRAM ESTACIONARAM AUMEMTARAM 
A inspeção do Quadro II onde figuram os aumentos de pêso, por cento em 12 dias e 22 dias, permite verificar-se que, duma maneira geral, e considerado cada frango individualmente, o aumento de pêso nesse intervalo de 10 dias é pouco apreciável.

O exame do Gráfico I, que se segue, mostra claramente que o criador deve escolher entre 12 e 16 dias. Depois do décimo segundo dia até o décimo sexto, 10 frangos estacionaram seu pêso e só 19 aumentaram. Após 16 dias os frangos já começam a perder pêso : 5 entre 16 e 18 dias, 12 entre 18 e 20 dias e 11 entre 20 e 22 dias.

\section{RESUMO E CONCLUSŐES}

Os AA. levaram a efeito uma experiência com 29 frangos da raça Rhode I. Red, que foram submetidos a um regime de engorda em gaiolas, com uma ração contendo aproximadamente $17 \%$ de proteina bruta, com o intuito de determinar o número ótimo de dias, necessário para o acabamento da operação.

Os dados conseguidos e expressos nos quadros I e II e no Gráfico I, permitiram verificar que em 12 dias conseguia-se um aumento de 443 gs., correspondendo a $25,4 \%$ do pêso inicial, aos 14 dias 483 gs., correspondendo a $27,7 \%$ do pêso inicial, o que é pouco menos do pêso final alcançado em 22 dias, que corresponde ao aumento médio de 521 gs., representando $30 \%$ do pêso inicial.

Um Gráfico construido com os dados obtidos mostra que houve uma paralisação de crescimento de 10 frangos no período compreendido entre o $12^{\circ}$. e o $16^{\circ}$. dia de tratamento e que, a partir desta data começou a verificar-se uma paralisação cada vez mais crescente acompanhada mesmo de uma diminuição de pêso que atingiu 5 frangos aos 18 dias, 12 aos 20 dias e 11 aos 22 dias.

Entrando em considerações econômicas, demonstra que ainda é vantajoso levar essa engorda até os 16 dias, embora o aumento máximo de pêso se verifique até 12 dias.

\section{ABSTRACT}

This paper deals with an experiment to determine the optimum period (number of days) in fattening chickens. Thirty chickens R. I. R. were numbered, weighed and feeded in crate, with one standard ration (17\% crude protein). 
The chickens were weighted every two days and the results obtained indicate the optimum is reached between 12 and 16 days of feeding.

It was observed that after 16 days the weights stop or decrease progressively as showed by the Grafic I.

\section{BIBLIOGRAFIA}

1 - TORRES, A. P. e TRIVELIN, 1949 - Experiencias de engorda de frangos, I - in Anais da E. S. A. L. Q. - U. S. P., 6: 127, Piracicaba, E. de São Paulo.

2-JULL, M. A. e MAW, W. A., 1923 - Experimental results on fat Chickens. Poultry Science, 2:99.

3-EWING, W. R., 1951 - Poultry Nutrition, 99, South Passadena, California. 


$$
\text { , }
$$

